\title{
INFluência de Herbicidas Na QuALIdAde da Matéria-Prima de GeNÓtipos DE CANA-DE-AÇÚCAR ${ }^{1}$
}

\author{
Effect of Herbicides on Raw the Matter Quality of Sugarcane Genotypes
}

\author{
GALON, L. ${ }^{2}$, FERREIRA, E.A. ${ }^{3}$, FERREIRA, F.A. ${ }^{4}$, SILVA, A.A. ${ }^{4}$, BARBOSA, M.H.P. ${ }^{4}$, REIS, M.R. ${ }^{2}$, \\ SILVA, A.F. ${ }^{2}$, CONCENÇO, G..$^{2}$, ASPIAZÚ, I. ${ }^{2}$, FRANÇA, A.C. ${ }^{2}$ e TIRONI, S.P. ${ }^{5}$
}

\begin{abstract}
RESUMO - Objetivou-se com este trabalho avaliar os efeitos de ametryn, trifloxysulfuronsodium e da mistura ametryn + trifloxysulfuron-sodium na qualidade da matéria-prima de genótipos de cana-de-açúcar. O experimento foi realizado em campo, em Argissolo VermelhoAmarelo, no delineamento de blocos casualizados em esquema de parcelas subdivididas, com quatro repetições. Os herbicidas ametryn $\left(2.000 \mathrm{~g} \mathrm{ha}^{-1}\right)$, trifloxysulfuron-sodium $\left(22,5 \mathrm{~g} \mathrm{ha}^{-1}\right)$ e a mistura comercial de ametryn + trifloxysulfuron-sodium $\left(1.463+37,0 \mathrm{~g} \mathrm{ha}^{-1}\right)$, aplicados em pós-emergência inicial da cultura, mais uma testemunha capinada foram alocados nas parcelas. Nas subparcelas foram dispostos dez genótipos de cana-de-açúcar: RB72454, RB835486, RB855113, RB855156, RB867515, RB925211, RB925345, RB937570, RB947520 e SP80-1816. Foram avaliadas por ocasião da colheita, realizada aos 430 dias após o plantio, as características: sólidos solúveis totais (Brix), pureza do caldo, fibra, sacarose aparente e produtividade de colmos e de açúcar, referentes à qualidade da matéria-prima dos genótipos. Para facilitar a interpretação dos resultados, todas as características avaliadas foram transformadas em porcentagens em relação à testemunha capinada (sem herbicida). Observaram-se efeitos diferenciados dos herbicidas sobre os genótipos, sendo o RB855156 e o RB835486 os que tiveram a produtividade de colmos e de açúcar mais afetada ao se aplicar. Houve queda na produtividade de colmos e de açúcar no genótipo RB855113 quando este foi tratado com a mistura (ametryn + trifloxysulfuron-sodium). Nenhum dos genótipos foi afetado pelo herbicida ametryn em aplicação isolada.
\end{abstract}

Palavras-chave: Saccharum spp., ametryn, trifloxysulfuron-sodium, mistura herbicida.

ABSTRACT - The objective of this study was to evaluate the effects of ametryn, trifloxysulfuronsodium and ametryn + trifloxysulfuron-sodium mix on the raw matter quality of sugarcane genotypes. The experiment was conducted in the field, in a Paleudult, using a split-plot design with four replications. The herbicides ametryn (2.000 $\left.\mathrm{g} \mathrm{ha}^{-1}\right)$, trifloxysulfuron-sodium $\left(22.5 \mathrm{~g} \mathrm{ha}^{-1}\right)$ and the commercial mixture of ametryn + trifloxysulfuron-sodium $(1.463+37,0 \mathrm{~g} \mathrm{ha}-1)$, applied in post initial emergence of the crop, plus a hoed control, were allocated in the plots. Ten sugarcane genotypes were arranged in the split-plots: RB72454, RB835486, RB8551 13, RB855156, RB867515, RB925211, RB925345, RB937570, RB947520 and SP80-1816. A harvest time, 430 days after planting, the following characteristics were assessed: total soluble-solids (Brix), broth purity, fiber, apparent sucrose and sugar and stem productivity, regarding the raw matter quality of the genotypes. To facilitate interpretation of the results, all the evaluated characteristics were converted into percentages in relation with the hoed control (no herbicide). Different herbicide effects on the genotypes were observed, with RB855156 and RB835486 presenting the lowest stem and sugar yield. Among the herbicides, trifloxysulfuron-sodium had the greatest influence on these characteristics. There was a decrease in stem and sugar yield in genotype RB8551 13 treated with the mixture (ametryn + trifloxysulfuron-sodium). None of the genotypes was affected by the herbicide ametryn, when applied alone.

Keywords: Saccharum spp., ametryn, trifloxysulfuron-sodium, herbicide mixture.

Recebido para publicação em 25.2.2008 e na forma revisada em 15.5.2008.

2 Engōo-Agr ${ }^{\circ}$., M.Sc., Doutorando no Programa de Pós-Graduação em Fitotecnia, Departamento de Fitotecnia, Universidade Federal de Viçosa - DFT/UFV, 36570-000 Viçosa-MG, Bolsista do CNPq-Brasil, <galonleandro@ig.com.br>; ${ }^{4}$ Prof. do DFT/UFV, Bolsista em Produtividade de Pesquisa do CNPq; ${ }^{3}$ Eng $^{0}-$ Agr $^{0}$., D.Sc., Pós-Doutorado DFT/UFV; ${ }^{5}$ Eng $^{0}-$ Agr $^{\circ}$., Mestrando no DFT/UFV. 


\section{INTRODUÇÃO}

Atualmente a cultura da cana-de-açúcar é a melhor alternativa para a produção do etanol do ponto de vista econômico, energético e ambiental (Andreoli \& Souza, 2006). Contudo, o aumento da produtividade de colmos é fortemente influenciado por alguns fatores, como: clones a serem cultivados, características físicas e químicas do solo, clima e competição das plantas daninhas. Entre esses fatores, as espécies daninhas, quando não controladas de modo adequado, podem limitar o desenvolvimento e a produtividade da cultura, dificultar a colheita e reduzir a longevidade do canavial (Procópio et al., 2004). Por esse motivo, o controle das plantas daninhas é prática obrigatória nas lavouras de cana-de-açúcar, sendo realizado quase que exclusivamente com o uso de herbicidas. O uso generalizado do método químico de controle das plantas daninhas se deve ao cultivo de grandes áreas, à praticidade, à eficácia, ao baixo custo e, principalmente, à utilização de menor quantidade de mão-de-obra quando comparado com outros métodos de controle. Os elevados danos causados pelas plantas daninhas à cultura da cana-de-açúcar ocorrem porque esta cultura apresenta desenvolvimento inicial lento, o que torna longo o período em que o canavial necessita estar livre da interferência das plantas daninhas (PCPI), variando entre 50 e 130 dias (Procópio et al., 2004; Kuva et al., 2000, 2003, 2008). Esse fato também justifica o elevado consumo, nessa cultura, de herbicidas que apresentam longo efeito residual no solo (Procópio et al., 2004).

Além do impacto desses produtos no solo, o uso intensivo de herbicidas pode causar efeitos diretos e/ou indiretos no crescimento e desenvolvimento e, às vezes, na qualidade do produto colhido (Das et al., 2003; Rizzardi et al., 2003). Na cana-de-açúcar, escassos são os trabalhos desenvolvidos para avaliar a seletividade e os efeitos dos herbicidas sobre os componentes da produtividade e da qualidade da matéria-prima dos colmos (Victoria Filho \& Camargo, 1980; Velini et al., 2000; Negrisoli et al., 2004; Azania et al., 2005; Barela \& Christoffoleti, 2006).

Em dez variedades de cana-de-açúcar a mistura de oxyfluorfen + ametryn não causou efeitos sobre a produtividade e na qualidade da matéria-prima dos colmos (Velini et al., 2000). Esses herbicidas apresentaram-se seletivos quando aplicados em pré ou em pósemergência da cultura. Entretanto, Azania et al. (2005) ao testarem os herbicidas diuron + hexazinone, azafenidin + hexazinone, metribuzin e isoxaflutole em solos de textura muito argilosa (61\% de argila, $24 \%$ de areia e $15 \%$ de silte), e Barela \& Christoffoleti (2006) ao estudarem os herbicidas sulfentrazone, tebuthiuron, metribuzin, ametryn, diuron, clomazone, pendimethalin e diuron + hexazinone em um Latossolo VermelhoAmarelo distrófico álico de textura arenosa, relataram que esses produtos alteraram de forma negativa a qualidade da matéria-prima da cana-de-açúcar. Segundo Azania et al. (2005) os efeitos negativos dos herbicidas ocorrem, principalmente, quando as plantas de cana-de-açúcar encontram-se em estádios jovens. Essa intoxicação, dependendo do genótipo cultivado, das condições edafoclimáticas da região e, sobretudo, das características do herbicida utilizado, poderá ou não afetar a produtividade e a qualidade da matéria-prima da cana-de-açúcar, como as porcentagens de sólidos solúveis totais do caldo (Brix), fibra, sacarose aparente (PCC) e pureza do caldo (Victoria Filho, 1980; Paranhos, 1987; Delgado et al., 1994; Velini et al., 2000; Barela \& Christoffoleti, 2006).

Atualmente os programas de melhoramento genético estão liberando e protegendo cultivares de cana-de-açúcar, cada vez mais produtivos, com maior resistência às doenças e pragas. Entretanto, são poucos os trabalhos desenvolvidos com os cultivares mais modernos que têm relatado maior ou menor tolerância de genótipos de cana-de-açúcar a herbicidas (Oliveira et al., 2004; Ferreira et al., 2005). Além disso, são escassos os conhecimentos sobre ação de herbicidas ocasionando alterações nos componentes da produtividade e da qualidade da matéria-prima da cultura. Acredita-se que a aplicação de herbicidas em estádio tardio da cultura possa elevar os indices de intoxicação, limitando a produtividade e resultando em mudanças fisiológicas, que podem ocasionar efeitos negativos na qualidade da matéria-prima dos colmos colhidos (Azania et al., 2006). Reis et al. (2008) relataram menor acúmulo de micronutrientes e também no crescimento da cana-de-açúcar 
quando esta foi tratada com os herbicidas ametryn, trifloxysulfurom-sodium e 2,4-D. Esse fato poderá vir a causar efeitos adversos na fisiologia, podendo reduzir a qualidade da matéria-prima dos colmos no momento da colheita.

No mercado brasileiro estão registrados 42 ingredientes ativos e 189 marcas comerciais de herbicidas para a cana-de-açúcar (AGROFIT, 2008). Entre outros produtos, destacam-se o ametryn e trifloxysulfuron-sodium aplicados de forma isolada ou em mistura formulada comercialmente. O ametryn é um dos herbicidas mais empregados para controle de diversas monocotiledôneas e dicotiledôneas, sendo recomendado em pré-emergência e pós-emergência inicial; ele apresenta baixa toxicidade para animais e humanos. Já o trifloxysulfuron-sodium está registrado no Brasil para o controle de dicotiledôneas, algumas gramíneas e ciperáceas em pós-emergência da cana-de-açúcar. A mistura comercial de ametryn + trifloxysulfuron-sodium possui amplo espectro de ação e ótima seletividade para essa cultura, porém seu comportamento para novos genótipos de cana-de-açúcar ainda é pouco estudado (Rodrigues \& Almeida, 2005; Syngenta, 2008). Para outros herbicidas, Velini et al. (2000), Ferreira et al. (2005) e Barela \& Christoffoleti (2006) relatam que cultivares de cana-de-açúcar apresentam respostas diferenciadas, tendo como consequência frequentes intoxicações; quando estas forem severas, podem ocasionar queda tanto da produtividade como da qualidade da matéria-prima da cultura. Mais informações sobre os atuais herbicidas disponiveis no mercado e sua ação sobre novos genótipos são necessárias para a recomendação segura de produtos destinados ao controle de plantas daninhas nas lavouras de cana-de-açúcar do Brasil. Assim, objetivouse com este trabalho avaliar os efeitos de ametryn, trifloxysulfuron-sodium e da mistura formulada comercialmente de ametryn + trifloxysulfuron-sodium nas características tecnológicas de novos genótipos de cana-deaçúcar.

\section{MATERIAL E MÉTODOS}

O experimento foi conduzido a campo no Centro Experimental de Pesquisa de Cana-deAçúcar (CECA) da Universidade Federal de Viçosa (UFV), município de Oratórios-MG, na latitude de $20^{\circ} 20^{\prime} \mathrm{S}$ e longitude de $43^{\circ} 48^{\prime} \mathrm{W}$, em um Argissolo Vermelho-Amarelo (Embrapa, 2006). O plantio foi realizado em sulcos feitos após o preparo do solo, pelo sistema convencional de cultivo. A adubação foi realizada no momento do plantio, com base nos resultados da análise do solo (Tabela 1) e nas recomendações para a cultura (CFSEMG, 1999). Plantaram-se dez linhas de cana-de-açúcar, com $10 \mathrm{~m}$ de comprimento, espaçadas de 1,40 m, sendo cada linha constituída por um genótipo, o que representou as unidades experimentais.

O plantio dos genótipos de cana-de-açúcar foi realizado em 27/4/2007, na densidade de 16 gemas $\mathrm{m}^{-1}$, sendo os colmos dentro dos sulcos picados em toletes de três a cinco gemas

Tabela 1 - Análise química do solo Argissolo Vermelho-Amarelo utilizado no experimento. Oratórios-MG, 2007

\begin{tabular}{|c|c|c|c|c|c|c|c|c|}
\hline \multirow{2}{*}{\multicolumn{2}{|c|}{ Camada amostrada }} & $\mathrm{pH}$ & $\mathrm{P}$ & $\mathrm{K}^{+}$ & $\mathrm{H}+\mathrm{Al}$ & $\mathrm{Al}^{3+}$ & $\mathrm{Ca}^{2+}$ & $\mathrm{Mg}^{2+}$ \\
\hline & & $\left(\mathrm{H}_{2} \mathrm{O}\right)$ & \multicolumn{3}{|c|}{$\left(\mathrm{mg} \mathrm{dm}^{-3}\right)$} & \multicolumn{3}{|c|}{$\left(\mathrm{cmol}_{\mathrm{c}} \mathrm{dm}^{-3}\right)$} \\
\hline \multicolumn{2}{|c|}{$0-10 \mathrm{~cm}$} & 5,1 & 4,5 & 33 & 2,15 & 0,2 & 1,5 & 0,7 \\
\hline SB & CTC (t) & CTC (T) & $\mathrm{v}$ & $\mathrm{m}$ & $\mathrm{MO}$ & Argila & Areia & Silte \\
\hline \multicolumn{3}{|c|}{$\left(\mathrm{cmol}_{\mathrm{c}} \mathrm{dm}^{-3}\right)$} & \multicolumn{2}{|c|}{$(\%)$} & \multicolumn{2}{|c|}{$\left(\right.$ dag kg $\left.^{-1}\right)$} & \multicolumn{2}{|c|}{$(\%)$} \\
\hline 2,28 & 2,48 & 2,48 & 51 & 8,0 & 0,9 & 39 & 43 & 18 \\
\hline
\end{tabular}

1/ Análise realizada no Laboratório de Análise de Solos Viçosa Ltda. pH: em água, relação 1:2,5. P-K: extrator Mehlich-1. Ca-Mg e Al: extrator $\mathrm{KCl}-1 \mathrm{~mol} \mathrm{~L}{ }^{-1} \cdot \mathrm{H}+\mathrm{Al}$ : extrator acetato de cálcio $0,5 \mathrm{~mol} \mathrm{~L}^{-1}-\mathrm{pH} 7,0$. $\mathrm{SB}$ : soma de bases trocáveis. CTC (t): capacidade de troca catiônica efetiva. CTC (T): capacidade de troca catiônica a pH 7,0. v: saturação de bases. m: saturação de alumínio. MO: matéria orgânica $=$ C.org x 1,724 - Walkley-Black. 
e cobertos com camada de solo com aproximadamente $5 \mathrm{~cm}$.

O delineamento experimental utilizado foi de blocos casualizados, arranjado em parcelas subdivididas com quatro repetições. Nas parcelas alocaram-se três herbicidas [ametryn (Metrimex SC ${ }^{\circledR}$ 500), trifloxysulfuron-sodium $\left(\right.$ Envoke $\left.^{\circledR}\right)$ e a mistura formulada ametryn + trifloxysulfuron-sodium (Krismat ${ }^{\circledR}$ )] mais uma testemunha capinada. Nas subparcelas, foram dispostos dez genótipos de cana-de-açúcar (RB72454, RB835486, RB855113, RB855156, RB867515, RB925211, RB925345, RB937570, RB947520 e SP80-1816). As doses utilizadas dos herbicidas foram as recomendadas para a cultura: $2.000 \mathrm{~g} \mathrm{ha}^{-1}$ de ametryn, 22,5 $\mathrm{g} \mathrm{ha}^{-1} \mathrm{de}$ trifloxysulfuron-sodium e $1.463+37,0 \mathrm{~g} \mathrm{ha}^{-1}$ para a mistura formulada de ametryn + trifloxysulfuron-sodium. Os herbicidas foram aplicados em pós-emergência inicial da canade-açúcar, aos 70 dias após o plantio, com pulverizador costal de precisão pressurizado a $\mathrm{CO}_{2}$, munido com barra de $2 \mathrm{~m}$ - acoplados a esta quatro pontas de pulverização da série TT 110.02, espaçadas de 0,5 m - e calibrado para aplicar o equivalente a $150 \mathrm{~L} \mathrm{ha}^{-1}$ de calda. No momento da aplicação a temperatura era de $23{ }^{\circ} \mathrm{C}$ e a velocidade do vento, de $5 \mathrm{~km} \mathrm{~h}^{-1}$.

As variáveis avaliadas foram: sólidos solúveis totais - brix (\%), pureza de caldo (\%), fibra (\%), porcentagem de sacarose - PCC (\%), produtividade de colmos - TCH $\left(\mathrm{t} \mathrm{ha}^{-1}\right)$ e de açúcar - TPH $\left(\mathrm{t} \mathrm{ha}^{-1}\right)$, sendo essas características componentes da qualidade da matériaprima da cana-de-açúcar, avaliadas por ocasião da colheita, aos 430 dias após o plantio dos genótipos.

Para estimar a produtividade de colmos, foram cortadas as plantas de todas as unidades experimentais rente ao solo, despalhadas, despontadas e separando os colmos do restante da planta; posteriormente, elas foram pesadas e os valores convertidos em $\mathrm{t}$ ha ${ }^{-1}$. A determinação do brix (\%), da pureza de caldo (\%), da fibra (\%) e da porcentagem de sacarose foi feita coletando-se amostras compostas de dez colmos industrializáveis de cada tratamento, após a determinação da produtividade. Os colmos dessas amostras foram pesados, passados em picadeiras de forragem e homogeneizados. Uma amostra de $500 \mathrm{~g}$ de colmos foi prensada, quantificando-se a seguir o volume de caldo e o teor de fibras. Nesse caldo, determinaram-se os teores de sólidos solúveis e de sacarose. A produtividade de açúcar $\left(\mathrm{t} \mathrm{ha}^{-1}\right)$ foi estimada pela fórmula: TPH $=[(\mathrm{TCH} x$ PCC)/100], em que TCH: produtividade de colmos e PCC: porcentagem de sacarose (\%). Os procedimentos analíticos e os cálculos adotados na avaliação da qualidade da matériaprima seguiram a metodologia descrita por Caldas (1998) e Fernandes (2003). As análises da matéria-prima foram efetuadas pelo laboratório de análises tecnológicas de cana-deaçúcar da Usina da Jatiboca, município de Urucânia-MG.

Os dados referentes às variáveis foram transformados em porcentagem, em relação à testemunha, e posteriormente analisados quanto à homocedasticidade, sendo submetidos logo em seguida à análise de variância. Após atenderem às premissas propostas anteriormente, efetuou-se o teste de agrupamento de médias de Scott \& Knott (1974). A probabilidade de erro aplicada em todos os testes foi de $\mathbf{p} \leq 0,05$.

\section{RESULTADOS E DISCUSSÃO}

Não houve interação entre herbicidas e genótipos com relação aos componentes da qualidade da matéria-prima (brix, fibra e PCC). Quanto às demais características, houve interação entre esses fatores. Os herbicidas influenciaram negativamente a qualidade da matéria-prima, em comparação com o tratamento sem herbicida. Houve reduções de 3,10 e $4 \%$ em brix, fibra e PCC, respectivamente (Tabela 2). Os genótipos não diferiram entre si em relação às características da qualidade da matéria-prima (Tabela 3). Velini et al. (2000) também não verificaram efeitos da mistura dos herbicidas oxyfluorfen + ametryn sobre a qualidade da matéria-prima dos colmos e a produtividade do cultivar de cana-de-açúcar RB72454.

Os genótipos RB835486, RB855113 e RB937570 não diferiram da testemunha sem herbicida quando se aplicaram ametryn, trifloxysulfuron-sodium e ametryn + trifloxysulfuron-sodium, para a porcentagem de pureza do caldo (Tabela 4). Para os genótipos RB855156 e RB947520, os tratamentos com os herbicidas ametryn e ametryn 
+ trifloxysulfuron-sodium diferiram da testemunha quanto a essa característica, com redução de aproximadamente $2 \%$. Quanto aos genótipos RB925345 e SP80-1816, apenas o ametryn diferiu da testemunha, e o RB867515 demonstrou diferença para ametryn + trifloxysulfuron-sodium em relação à testemunha capinada. No cultivar RB72454, observou-se diferença para os tratamentos que envolveram o ametryn e o ametryn + trifloxysulfuronsodium, e, para o genótipo RB925211, houve diferença para trifloxysulfuron-sodium e ametryn + trifloxysulfuron-sodium.

Para todos os herbicidas, constatou-se diferença entre os cultivares com relação à porcentagem de pureza do caldo (Tabela 4). O ametryn promoveu redução de cerca de $2 \%$

Tabela 2 - Influência de herbicidas aplicados isolados ou em mistura formulada nos componentes da qualidade biológica de genótipos de cana-de-açúcar

\begin{tabular}{|l|c|c|c|}
\hline Herbicida & Brix (\%) & Fibra (\%) & $\operatorname{PCC}^{-3 /}(\%)$ \\
\hline $\mathrm{TC}^{1 /}$ & $100,00 \mathrm{a}^{\frac{2}{}}$ & $100,00 \mathrm{a}$ & $100,00 \mathrm{a}$ \\
\hline HA & $97,52 \mathrm{~b}$ & $93,30 \mathrm{c}$ & $96,64 \mathrm{~b}$ \\
\hline HB & $97,70 \mathrm{~b}$ & $90,70 \mathrm{c}$ & $97,39 \mathrm{~b}$ \\
\hline HC & $98,45 \mathrm{~b}$ & $96,49 \mathrm{~b}$ & $96,99 \mathrm{~b}$ \\
\hline CV (\%) & 2,31 & 9,26 & 4,71 \\
\hline
\end{tabular}

1/ TC: testemunha capinada; HA: ametryn (2.000 $\left.\mathrm{g} \mathrm{ha}^{-1}\right)$; HB: trifloxysulfuron-sodium $\left(22,5 \mathrm{~g} \mathrm{ha}^{-1}\right) ; \mathrm{HC}$ : ametryn + trifloxysulfuron-sodium $\left(1.673+37,0 \mathrm{~g} \mathrm{ha}^{-1}\right)$. ํㅡㄹédias seguidas de mesmas letras, na coluna, constituem grupos homogêneos, conforme Scott-Knott $(\mathrm{p} \leq 0,05) \cdot \stackrel{3}{ }$ Porcentagem de sacarose.

Tabela 3 - Porcentagem em relação à testemunha (100\%) dos componentes da qualidade da matéria-prima de genótipos de cana-de-açúcar

\begin{tabular}{|l|c|c|c|}
\hline \multicolumn{1}{|c|}{ Genótipo } & Brix (\%) & Fibra (\%) & PCC $^{2 /}(\%)$ \\
\hline RB72454 & $98,43 \mathrm{a}^{\mathrm{Il}}$ & $94,27 \mathrm{a}$ & $98,03 \mathrm{a}$ \\
\hline RB835486 & $96,23 \mathrm{a}$ & $97,36 \mathrm{a}$ & $94,94 \mathrm{a}$ \\
\hline RB855113 & $99,66 \mathrm{a}$ & $95,89 \mathrm{a}$ & $99,39 \mathrm{a}$ \\
\hline RB855156 & $98,65 \mathrm{a}$ & $90,78 \mathrm{a}$ & $97,78 \mathrm{a}$ \\
\hline RB867515 & $97,94 \mathrm{a}$ & $96,54 \mathrm{a}$ & $97,23 \mathrm{a}$ \\
\hline RB925211 & $98,35 \mathrm{a}$ & $94,09 \mathrm{a}$ & $97,15 \mathrm{a}$ \\
\hline RB925345 & $98,25 \mathrm{a}$ & $97,17 \mathrm{a}$ & $98,14 \mathrm{a}$ \\
\hline RB937570 & $99,28 \mathrm{a}$ & $97,50 \mathrm{a}$ & $99,11 \mathrm{a}$ \\
\hline RB947520 & $99,06 \mathrm{a}$ & $94,53 \mathrm{a}$ & $97,75 \mathrm{a}$ \\
\hline SP80-1816 & $98,31 \mathrm{a}$ & $93,12 \mathrm{a}$ & $98,03 \mathrm{a}$ \\
\hline CV (\%) & 2,46 & 7,61 & 3,60 \\
\hline
\end{tabular}

${ }^{1 /}$ Médias seguidas de mesmas letras, na coluna, constituem grupos homogêneos, conforme Scott-Knott ( $\mathrm{p} \leq 0,05) .{ }^{2} /$ Porcentagem de sacarose. nessa variável em relação à testemunha, para os genótipos RB72454, RB855156, RB925345, RB947520 e SP80-1816, e o trifloxysulfuronsodium, cerca de 3\% para o cultivar RB855156 e aproximadamente $2,5 \%$ para os genótipos RB925211 e RB947520. O ametryn + trifloxysulfuron-sodium ocasionou influência sobre os genótipos RB72454, RB867515 e RB925211, com redução dessa variável em cerca de $2 \%$, comparando-se com a testemunha. Azania et al. (2005), ao trabalharem com os herbicidas metribuzin, isoxaflutole e misturas destes, constataram que a aplicação em pós-emergência tardia alterou a qualidade de matériaprima, brix, pureza do caldo e a produtividade de colmos.

Observou-se, para a produtividade de colmos da cana-de-açúcar, que os genótipos RB867515, RB925345, RB937570, RB947520 e SP80-1816 tratados com os três herbicidas não apresentaram diferença em relação ao tratamento sem herbicida (Tabela 5). Destacase que o RB855156 foi influenciado negativamente por todos os herbicidas testados. Cruz \& Gurgel (1983), ao trabalharem com hexazinone e diuron e suas misturas no controle de capim-colchão em cana-de-açúcar,

Tabela 4 - Pureza do caldo (\%) em função de genótipos de canade-açúcar e da aplicação de herbicidas isolados ou em mistura formulada

\begin{tabular}{|l|c|c|c|c|}
\hline \multirow{2}{*}{ Genótipo } & \multicolumn{4}{|c|}{ Herbicida } \\
\cline { 2 - 5 } & $\mathrm{TC}^{1 /}$ & HA & HB & HC \\
\hline RB72454 & $100,00 \mathrm{aA}^{2 /}$ & $98,44 \mathrm{bB}$ & $99,38 \mathrm{aA}$ & $98,58 \mathrm{bB}$ \\
\hline RB835486 & $100,00 \mathrm{aA}$ & $99,33 \mathrm{aA}$ & $99,94 \mathrm{aA}$ & $99,55 \mathrm{aA}$ \\
\hline RB855113 & $100,00 \mathrm{aA}$ & $99,76 \mathrm{aA}$ & $99,45 \mathrm{aA}$ & $98,97 \mathrm{aA}$ \\
\hline RB855156 & $100,00 \mathrm{aA}$ & $98,22 \mathrm{bB}$ & $96,98 \mathrm{bB}$ & $99,27 \mathrm{aA}$ \\
\hline RB867515 & $100,00 \mathrm{aA}$ & $99,21 \mathrm{aA}$ & $99,56 \mathrm{aA}$ & $97,64 \mathrm{bB}$ \\
\hline RB925211 & $100,00 \mathrm{aA}$ & $99,08 \mathrm{aA}$ & $97,47 \mathrm{bB}$ & $97,71 \mathrm{bB}$ \\
\hline RB925345 & $100,00 \mathrm{aA}$ & $97,65 \mathrm{bB}$ & $99,07 \mathrm{aA}$ & $98,95 \mathrm{aA}$ \\
\hline RB937570 & $100,00 \mathrm{aA}$ & $99,76 \mathrm{aA}$ & $99,46 \mathrm{aA}$ & $100,00 \mathrm{aA}$ \\
\hline RB947520 & $100,00 \mathrm{aA}$ & $98,53 \mathrm{bB}$ & $97,58 \mathrm{bB}$ & $99,41 \mathrm{aA}$ \\
\hline SP80-1816 & $100,00 \mathrm{aA}$ & $97,86 \mathrm{bB}$ & $98,94 \mathrm{aA}$ & $99,55 \mathrm{aA}$ \\
\hline CV (\%) parcela & \multicolumn{5}{|c|}{0,64} \\
\hline CV (\%) subparcela & \multicolumn{5}{|c}{0,90} \\
\hline
\end{tabular}

1/ TC: testemunha capinada; HA: ametryn $\left(2.000 \mathrm{~g} \mathrm{ha}^{-1}\right)$; HB: trifloxysulfuron-sodium $\left(22,5 \mathrm{~g} \mathrm{ha}^{-1}\right) ; \mathrm{HC}$ : ametryn + trifloxysulfuron-sodium $\left(1.673+37,0 \mathrm{~g} \mathrm{ha}^{-1}\right) .{ }^{2 /}$ Médias seguidas de mesmas letras minúsculas, na coluna, e maiúsculas, na linha constituem grupos homogêneos, conforme Scott-Knott $(\mathrm{p} \leq 0,05)$.

Planta Daninha, Viçosa-MG, v. 27, n. 3, p. 555-562, 2009 
não observaram diferença significativa na produção de colmos. Montório et al. (2008) observaram que os herbicidas tebuthiuron $\mathrm{e}$ as misturas tebuthiuron + diuron e diuron + ametryn reduziram a produção de colmos do cultivar RB835089 em 11, 17 e 5,5 t ha-1, respectivamente.

O ametryn ocasionou redução da produtividade de colmos de cerca de $8 \%$ em relação ao tratamento sem herbicida apenas no cultivar RB855156. O trifloxysulfuron-sodium provocou queda nessa variável de aproximadamente 9, 17 e 18\% nos cultivares RB72454, RB835486 e RB855156, respectivamente. O ametryn + trifloxysulfuron-sodium alterou de forma significativa a produtividade dos cultivares RB855113, RB855156 e RB925211, com quedas de 14, 10 e 10\%, respectivamente (Tabela 5). Freitas et al. (2004) ao estudarem a mistura ametryn + trifloxysulfuron-sodium, encontraram resultados semelhantes aos deste estudo, porém avaliaram a influência da mistura somente sobre o cultivar RB72454. Esses autores não observaram ainda a redução na produção de colmos para as misturas MSMA + diuron e diuron + paraquat. Ferreira et al. (2005) ao trabalharem com 15 genótipos de cana-de-açúcar, verificaram que os cultivares apresentam sensibilidade diferencial à mistura de ametryn + trifloxysulfuron-sodium; o RB855113 demonstrou ser o mais sensivel ao herbicida mesmo nas menores doses testadas. Nesse mesmo estudo, os cultivares SP80-1842, SP80-1816, SP79-1011 e RB957689 apresentaram média sensibilidade à mistura herbicida; no entanto, os autores avaliaram o efeito do herbicida sobre os cultivares de canade-açúcar em experimento conduzido em casa de vegetação. Azania et al. (2005) ao estudarem os efeitos do isoxaflutole sobre o cultivar RB835039 em campo, constataram que o herbicida altera a produtividade da canade-açúcar.

Comportamento semelhante ao da produtividade de colmos foi observado para a produtividade de açúcar, considerando que essas duas características apresentam relação direta (Tabela 6). Nesta característica também foi observada interação entre herbicidas e genótipos. Assim como na produtividade de colmos, as produtividades de açúcar dos genótipos RB867515, RB925345, RB937570, RB947520 e
Tabela 5 - Produtividade de colmos (\%) em função de genótipos de cana-de-açúcar e da aplicação de herbicidas isolados ou em mistura formulada

\begin{tabular}{|l|c|r|r|r|}
\hline \multirow{2}{*}{ Genótipo } & \multicolumn{4}{|c|}{ Herbicida } \\
\cline { 2 - 5 } & $\mathrm{TC}^{1 /}$ & HA & \multicolumn{1}{c|}{$\mathrm{HB}$} & $\mathrm{HC}$ \\
\hline RB72454 & $100,00 \mathrm{aA}^{2 /}$ & $95,92 \mathrm{aA}$ & $90,86 \mathrm{bB}$ & $100,00 \mathrm{aA}$ \\
\hline RB835486 & $100,00 \mathrm{aA}$ & $100,00 \mathrm{aA}$ & $83,10 \mathrm{cB}$ & $99,82 \mathrm{aA}$ \\
\hline RB855113 & $100,00 \mathrm{aA}$ & $98,84 \mathrm{aA}$ & $95,34 \mathrm{aA}$ & $86,53 \mathrm{bB}$ \\
\hline RB855156 & $100,00 \mathrm{aA}$ & $92,24 \mathrm{aB}$ & $81,69 \mathrm{cC}$ & $90,69 \mathrm{bB}$ \\
\hline RB867515 & $100,00 \mathrm{aA}$ & $96,30 \mathrm{aA}$ & $100,00 \mathrm{aA}$ & $99,11 \mathrm{bA}$ \\
\hline RB925211 & $100,00 \mathrm{aA}$ & $100,00 \mathrm{aA}$ & $99,32 \mathrm{aA}$ & $90,36 \mathrm{bB}$ \\
\hline RB925345 & $100,00 \mathrm{aA}$ & $98,51 \mathrm{aA}$ & $95,93 \mathrm{aA}$ & $100,00 \mathrm{aA}$ \\
\hline RB937570 & $100,00 \mathrm{aA}$ & $96,38 \mathrm{aA}$ & $99,31 \mathrm{aA}$ & $100,00 \mathrm{aA}$ \\
\hline RB947520 & $100,00 \mathrm{aA}$ & $99,46 \mathrm{aA}$ & $100,00 \mathrm{aA}$ & $100,00 \mathrm{aA}$ \\
\hline SP80-1816 & $100,00 \mathrm{aA}$ & $100,00 \mathrm{aA}$ & $100,00 \mathrm{aA}$ & $100,00 \mathrm{aA}$ \\
\hline CV (\%) parcela & \multicolumn{5}{|c|}{3,10} \\
\hline CV (\%) subparcela & 4,69 \\
\hline
\end{tabular}

1/ TC: testemunha capinada; HA: ametryn $\left(2.000 \mathrm{~g} \mathrm{ha}^{-1}\right)$; HB: trifloxysulfuron-sodium $\left(22,5 \mathrm{~g} \mathrm{ha}^{-1}\right)$; HC: ametryn + trifloxysulfuron-sodium $\left(1.673+37,0 \mathrm{~g} \mathrm{ha}^{-1}\right) .{ }^{2 /}$ Médias seguidas de mesmas letras minúsculas nas colunas e maiúsculas nas linhas constituem grupos homogêneos conforme Scott-Knott ( $\mathrm{p} \leq 0,05)$

Tabela 6 - Produtividade de açúcar (\%) em função de genótipos de cana-de-açúcar e da aplicação de herbicidas isolados ou em mistura formulada

\begin{tabular}{|l|l|r|r|r|}
\hline \multirow{2}{*}{ Genótipo } & \multicolumn{4}{|c|}{ Herbicida } \\
\cline { 2 - 5 } & \multicolumn{1}{|c|}{ TC $^{1 /}$} & \multicolumn{1}{|c|}{ HA } & \multicolumn{1}{c|}{ HB } & \multicolumn{1}{c|}{ HC } \\
\hline RB72454 & $100,00 \mathrm{aA}^{2 /}$ & $96,00 \mathrm{aA}$ & $88,45 \mathrm{bB}$ & $100,00 \mathrm{aA}$ \\
\hline RB835486 & $100,00 \mathrm{aA}$ & $100,00 \mathrm{aA}$ & $77,67 \mathrm{cB}$ & $98,36 \mathrm{aA}$ \\
\hline RB855113 & $100,00 \mathrm{aA}$ & $98,39 \mathrm{aA}$ & $95,89 \mathrm{aA}$ & $88,98 \mathrm{bB}$ \\
\hline RB855156 & $100,00 \mathrm{aA}$ & $91,46 \mathrm{aB}$ & $83,51 \mathrm{bB}$ & $89,77 \mathrm{bB}$ \\
\hline RB867515 & $100,00 \mathrm{aA}$ & $94,57 \mathrm{aA}$ & $100,00 \mathrm{aA}$ & $98,74 \mathrm{aA}$ \\
\hline RB925211 & $100,00 \mathrm{aA}$ & $100,00 \mathrm{aA}$ & $97,47 \mathrm{aA}$ & $87,19 \mathrm{bB}$ \\
\hline RB925345 & $100,00 \mathrm{aA}$ & $98,94 \mathrm{aA}$ & $93,00 \mathrm{aA}$ & $100,00 \mathrm{aA}$ \\
\hline RB937570 & $100,00 \mathrm{aA}$ & $95,64 \mathrm{aA}$ & $99,25 \mathrm{aA}$ & $99,76 \mathrm{aA}$ \\
\hline RB947520 & $100,00 \mathrm{aA}$ & $99,09 \mathrm{aA}$ & $100,00 \mathrm{aA}$ & $98,85 \mathrm{aA}$ \\
\hline SP80-1816 & $100,00 \mathrm{aA}$ & $100,00 \mathrm{aA}$ & $100,00 \mathrm{aA}$ & $100,00 \mathrm{aA}$ \\
\hline CV (\%) parcela & \multicolumn{5}{|c|}{5,21} \\
\hline CV (\%) subparcela & \multicolumn{5}{|c}{5,92} \\
\hline
\end{tabular}

1/ TC: testemunha capinada; HA: ametryn $\left(2.000 \mathrm{~g} \mathrm{ha}^{-1}\right)$; HB: trifloxysulfuron-sodium $\left(22,5 \mathrm{~g} \mathrm{ha}^{-1}\right)$; $\mathrm{HC}$ : ametryn + trifloxysulfuron-sodium $\left(1.673+37,0 \mathrm{~g} \mathrm{ha}^{-1}\right) .{ }^{2 /}$ Médias seguidas de mesmas letras minúsculas, na coluna, e maiúsculas, na linha, constituem grupos homogêneos, conforme Scott-Knott $(\mathrm{p} \leq 0,05)$.

SP80-1816 não foram alteradas por nenhum dos produtos testados. O ametryn ocasionou redução de $18,5 \%$ na produtividade do genótipo RB855156, enquanto o trifloxysulfuron-sodium 
reduziu em cerca de 12,23 e $17 \%$ a produtividade de açúcar dos cultivares RB72454, RB835486 e RB855156, respectivamente. Para o ametryn + trifloxysulfuron-sodium, para a mesma variável em estudo, houve queda de aproximadamente 11,10 e $11 \%$, respectivamente para os genótipos RB855113, RB855156 e RB925211. Barela \& Christoffoleti (2006) ao trabalharem com a interação de herbicidas e nematicidas, observaram que os danos de intoxicação não se refletiram em perdas significativas de rendimento ou de qualidade da matéria-prima dos colmos. Segundo esses autores, esse fato possivelmente ocorre devido à capacidade de recuperação de injúrias apresentada pelo cultivar de cana-deaçúcar RB867515, o qual foi utilizado no estudo.

É conveniente ressaltar que, em vários trabalhos encontrados na literatura acerca do uso de herbicidas e seletividade desses produtos em genótipos de cana-de-açúcar, os pesquisadores relatam que há grande diferenciação entre cultivares utilizados e que a influência dos herbicidas sobre estes, em especial na qualidade da matéria-prima, deve-se em parte às características intrinsecas ou ao tipo de genótipo utilizado. Também as propriedades físico-químicas do herbicida aplicado para controle de plantas daninhas e, em algumas situações, até mesmo as condições edafoclimáticas da região onde é plantada a cana-de-açúcar podem alterar o desempenho da cultura.

Com base nos resultados, conclui-se que os herbicidas testados alteram de forma diferenciada as características relacionadas à qualidade da matéria-prima da cana-de-açúcar, como brix, fibra, porcentagem de sacarose e pureza do caldo, e principalmente a produtividade de colmos e de açúcar dos genótipos testados. Observou-se, para o genótipo RB855156, que a produtividade de colmos e de açúcar foi afetada por todos os herbicidas; o trifloxysulfuron-sodium foi o que mais influenciou essas características, além de ele ocasionar efeitos negativos também ao genótipo RB835486 para as mesmas variáveis avaliadas. O RB855113 foi influenciado de forma acentuada quanto à produtividade de colmos e de açúcar quando tratado com ametryn + trifloxysulfuron-sodium.

\section{AGRADECIMENTOS}

Ao Conselho Nacional de Desenvolvimento Científico e Tecnológico (CNPq-Brasil), pela concessão de bolsas.

\section{LITERATURA CITADA}

ANDREOLI, C.; SOUZA, S. P. Cana-de-açúcar: A melhor alternativa para conversão da energia solar e fóssil em etanol. Econ. Energia, v. 2, n. 59, p. 27-33, 2006.

AZANIA, C. A. M. et al. Seletividade de herbicidas. II Aplicação de herbicidas em pós-emergência inicial e tardia da cana-de-açúcar na época das chuvas. Planta Daninha, v. 23, n. 4, p. 669-675, 2005.

AZANIA, C. A. M. et al. Seletividade de herbicidas. III Aplicação de herbicidas em pós-emergência inicial e tardia da cana-de-açúcar na época da estiagem. Planta Daninha, v. 24, n. 3, p. 489-495, 2006.

BARELA, J. F.; CHRISTOFFOLETI, P. J. Seletividade de herbicidas aplicados em pré-emergência da cultura da cana-deaçúcar (RB867515) tratada com nematicidas. Planta Daninha, v. 24, n. 2, p. 371-378, 2006.

CALDAS, C. Manual de análises selecionadas para indústrias sucroalcooleiras. Maceió: Sindicato da Indústria do Açúcar e do Álcool no Estado de Alagoas, 1998. $422 \mathrm{p}$.

COMISSÃO DE FERTILIDADE DO SOLO DO ESTADO DE MINAS GERAIS. CFSEMG. Recomendações para o uso de corretivos e fertilizantes em Minas Gerais $\mathbf{-} \mathbf{5}^{\text {a }}$ aproximação. Viçosa, MG: Universidade Federal de Viçosa, 1999. 359 p.

CRUZ, L. S. P.; GURGEL, M. N. A. Efeitos de hexazinone e diuron, e suas misturas, no controle de capim-colchão (Digitaria sanguinalis (L.) Scop) em cana-de-açúcar (Saccharum spp). Planta Daninha, v. 6, n. 1, p. 15-20, 1983.

DAS, A. C.; DEBNATH, A.; MUKHERJEE, D. Effect of the herbicides oxadiazon and oxyfluorfen on phosphates solubilizing microorganisms and their persistence in rice fields. Chemosphere, v. 53, n. 5, p. 217-221, 2003.

DELGADO, A. A. et al. Composição da variedade de cana-deaçúcar IAC 64257. STAB, v. 13, n. 2, p. 23-27, 1994.

EMPRESA BRASILEIRA DE PESQUISA AGROPECUÁRIA - EMBRAPA. Centro Nacional de Pesquisa Agropecuária de Solos. Sistema brasileiro de classificação de solos. Rio de Janeiro: 2006. 412 p.

Planta Daninha, Viçosa-MG, v. 27, n. 3, p. 555-562, 2009 
FERNANDES, P. C. R. Cálculos na agroindústria de cana-de-açúcar. 2.ed. Piracicaba: STAB, 2003. 240 p.

FERREIRA, E. A. et al. Sensibilidade de cultivares de canade-açúcar à mistura trifloxysulfuron-sodium + ametryn Planta Daninha, v. 23, n. 1, p. 93-99, 2005.

FREITAS, S. P. et al. Controle químico de Rottboellia exaltata em cana-de-açúcar. Planta Daninha, v. 22, n. 3, p. 461-466, 2004.

KUVA, M. A. et al. Períodos de interferência das plantas daninhas na cultura da cana-de-açúcar. I - Tiririca. Planta Daninha, v. 18 , n. 2, p. 241-251, 2000.

KUVA, M.A. et al. Períodos de interferência das plantas daninhas na cultura da cana-de-açúcar. III - Capim-brachiaria (Brachiaria decumbens) e capim-colonião (Panicum maximum). Planta Daninha, v. 21, n. 1, p. 37-44, 2003.

KUVA, M. A. et al. Padrões de infestação de comunidades de plantas daninhas no agroecossistema de cana-crua. Planta Daninha, v. 26, n. 3, p. 549-557, 2008.

MONTÓRIO, G. A. et al. Seletividade de herbicidas sobre as características de produção de cana-de-açúcar utilizando-se suas testemunhas. Disponível em: $<$ http:// www.upf.br/rbherbicidas/download/RBH226>. Acesso em: 21 out. 2008

NEGRISOLI, E. et al. Seletividade de herbicidas aplicados em pré-emergência na cultura da cana-de-açúcar tratada com nematicidas. Planta Daninha, v. 22, n. 4, p. 567-575, 2004.

OLIVEIRA, R. A. et al. Crescimento e desenvolvimento de três cultivares de cana-de-açúcar, em cana-planta, no Estado do Paraná. Sci. Agr., v. 5, n. 1-2, p. 87-94, 2004
PARANHOS, S. B. Cana-de-açúcar. Cultivo e utilização. v.1-2, Campinas: Fundação Cargill, 1987. v. 2. 856 p.

PROCÓPIO, S. O.; SILVA, A. A.; VARGAS, L. Manejo e controle de plantas daninhas em cana-de-açúcar. In: VARGAS, L.; ROMAN, E. S., eds.. Manual de manejo e controle de plantas daninhas. Bento Gonçalves: Embrapa Uva e Vinho, 2004. p. $397-452$.

REIS, M. R. et al. Dinâmica de nutrientes em tecidos foliares de cana-de-açúcar após aplicação de herbicidas. Planta Daninha, v. 26, n. 1, p. 175-184, 2008.

RIZZARDI, M. A. et al. Ação de herbicidas sobre mecanismos de defesa das plantas aos patógenos. Ci. Rural, v. 33, n. 5 , p. $957-965,2003$

RODRIGUES, B. N.; ALMEIDA, F. R. Guia de herbicidas 5.ed. Londrina: Edição dos Autores, 2005. 591 p.

SCOTT, A.; KNOTT, M. Cluster-analysis method for grouping means in analysis of variance. Biometrics, v. 30, n. 3, p. 507-512, 1974.

\section{SISTEMA DE AGROTÓXICOS FITOSSANITÁRIOS -} AGROFIT. Disponível em: <http://extranet.agricultura.gov.br/ agrofit $>$. Acesso em: 19 set. 2008

SYNGENTA. Syngenta Foundation. Disponível em: $<$ http://www.syngenta.com>. Acesso em: 30 ago. 2008

VELINI, E. D. et al. Avaliação da seletividade da mistura de oxyfluorfen e ametryne, aplicada em pré e pós-emergência, a dez variedades de cana-de-açúcar (cana planta). Planta Daninha, v. 18, n. 2, p. 123-134, 2000

VICTÓRIA FILHO, R.; CAMARGO, P. N. Efeitos de herbicidas nos teores de macronutrientes e nas características tecnológicas da cana-de-açúcar (Saccharum spp.). I Misturas de herbicidas em pós-emergência. Planta Daninha, v. 3 , n. 2 , p. $96-107,1980$. 